Published in final edited form as:

Adv Parasitol. 2011 ; 76: 63-81. doi:10.1016/B978-0-12-385895-5.00003-7.

\title{
Gap Junctions and Chagas Disease
}

\author{
Daniel Adesse ${ }^{*}, \dagger$, Regina Coeli Goldenberg ${ }^{*}$, Fabio S. Fortes ${ }^{\ddagger}$, Jasmin $^{*}, \S$, Dumitru A. \\ lacobas $\S$, Sanda lacobas ${ }^{\S}$, Antonio Carlos Campos de Carvalho ${ }^{*}, \S$, Maria de Narareth

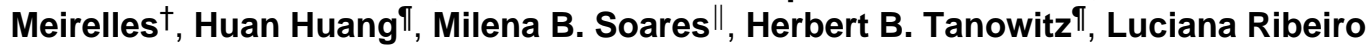 \\ Garzoni ${ }^{\dagger}$, and David C. Spray $§$ \\ *Instituto de Biofísica Carlos Chagas Filho, Universidade Federal do Rio de Janeiro, Brazil \\ †Instituto Oswaldo Cruz, Fundação Oswaldo Cruz, Rio de Janeiro, Brazil \\ ${ }^{\ddagger}$ Colegiado de Ciencias Biologicas e da Saude (CCBS), Centro Universitario Stadual da Zona \\ Oeste (UEZO), Rio de Janeiro, Brazil \\ §Dominick P. Purpura Department of Neuroscience, Albert Einstein College of Medicine, Bronx, \\ New York, USA \\ IDepartment of Pathology, Albert Einstein College of Medicine, Bronx, New York, USA \\ "Instituto Oswaldo Cruz, Fundação Oswaldo Cruz, Salvador, Bahia, Brazil
}

\section{Abstract}

Gap junction channels provide intercellular communication between cells. In the heart, these channels coordinate impulse propagation along the conduction system and through the contractile musculature, thereby providing synchronous and optimal cardiac output. As in other arrhythmogenic cardiac diseases, chagasic cardiomyopathy is associated with decreased expression of the gap junction protein connexin $43(\mathrm{Cx} 43)$ and its gene. Our studies of cardiac myocytes infected with Trypanosoma cruzi have revealed that synchronous contraction is greatly impaired and gap junction immunoreactivity is lost in infected cells. Such changes are not seen for molecules forming tight junctions, another component of the intercalated disc in cardiac myocytes. Transcriptomic studies of hearts from mouse models of Chagas disease and from acutely infected cardiac myocytes in vitro indicate profound remodelling of gene expression patterns involving heart rhythm determinant genes, suggesting underlying mechanisms of the functional pathology. One curious feature of the altered expression of $\mathrm{Cx} 43$ and its gene expression is that it is limited in both extent and location, suggesting that the more global deterioration in cardiac function may result in part from spread of damage signals from more seriously compromised cells to healthier ones.

\subsection{INTRODUCTION}

Gap junction channels are composed of the connexin family of transmembrane proteins that assemble as end-to-end alignments of hexameric connexin subunits (Fig. 3.1). These structures form intercellular conduits that are permeable both to current-carrying ions (primarily $\mathrm{K}^{+}$) and to second messenger molecules with molecular mass $(\mathrm{Mr})<1 \mathrm{kDa}$ such as $\mathrm{Ca}^{2+}, \mathrm{IP}_{3}$ and cyclic AMP. The connexin gene family in mammals includes more than 20 isoforms encoded by separate genes (Söhl and Willecke, 2004), and such isoforms are named according to the molecular weight (in $\mathrm{kDa}$ ) of the protein predicted from its cDNA (Goodenough et al., 1996); genes encoding connexins follow a different nomenclature, where they are divided into several subfamilies and identified according to the order of their discovery. Gap junction channels are critical in the heart, where they mediate synchronized rhythmic contractions and maintain cardiac homeostasis by allowing the free diffusion of metabolites between cardiac myocytes. Connexin 43 (Cx43, encoded by the Gjal gene in 
rodents and by GJA1 in humans) is the most abundant gap junction protein in ventricular myocytes, being localized at intercalated discs in normal myocardium (see Duffy et al., 2006 for review). In addition, $\mathrm{Cx} 40$ (encoded by Gja5) and connexin $45(\mathrm{Cx} 45, G j c 1)$ are found more prominently in atrium in the working myocardium and in the conduction system, and connexin37 (Cx37, Gja4) is a major component of gap junctions between endothelial cells in the vessel wall.

Gap junction function and distribution within and between cells are affected by phosphorylation state of the connexins that form them and by other factors including intracellular pH and protein-protein interactions (see Hervé et al., 2004; Spray et al., 2001 for reviews). In diverse cardiac disease states, such as myocardial infarction and ischaemia, significant remodelling of the distribution of $\mathrm{Cx} 43$ occurs in ventricles, resulting in disorganization of normal microconduction pathways and arrhythmias (Severs, 2001); similarly, altered $\mathrm{Cx} 40$ distribution has been associated with atrial fibrillation (see Chaldoupi et al., 2009 for review).

Studies of alterations in cardiac myocytes during in vitro infection with Trypanosoma cruzi indicate that the parasite is capable of impairing host cell functioning through alterations in cell-cell communication (de Carvalho et al., 1992). Such an effect is expected to be of particular importance in the heart, where maintenance of synchronous contractions requires functional gap junctions (see Duffy et al., 2006; Severs et al., 2006 for reviews). Because gap junctional communication is important in normal cardiac conduction, and because chagasic cardiomyopathy resulting from infection with $T$. cruzi is associated with arrhythmias, a major focus of our laboratories has been the examination of the expression and distribution of $\mathrm{Cx} 43$ in widely used in vivo and in vitro models of infection.

Chagas disease has both acute and chronic stages, and in both, there may be cardiac involvement. While myocarditis may be observed during acute infection, chronic infection may result in arrhythmias, congestive heart failure or thromboembolic events (see Tanowitz et al., 1992, 2009 for review). Dilated cardiomyopathy usually occurs many years after the initial infection. There is little tissue parasitism in the chronic stage, but conduction pathways are damaged with resultant disturbed heart rhythm. Mechanisms postulated by various authors to explain the development of chronic chagasic heart disease include autoimmunity, microvascular disturbances and autonomic nervous system derangements (see Marin-Neto et al., 2007 for review). Clearly, there is evidence for each: inflammation is present in the absence of appreciable parasite burden; verapamil is therapeutically useful because it alleviates vasospasms; and there is destruction of autonomic ganglia in chronic disease. However, mechanisms responsible for the arrhythmogenic nature of the disease have received little attention.

\subsection{LOSS OF GAP JUNCTIONS AND COUPLING IN RODENT CHAGASIC CARDIOMYOPATHY}

In early studies, our laboratory groups examined spontaneous beating rate of cultures of $T$. cruzi-infected mouse and rat cardiac myocytes, finding opposite effects in the two murine species (Aprigliano et al., 1993; Bergdolt et al., 1994; de Carvalho et al., 1992; see de Carvalho et al., 1994 for review): in infected mouse cells, beat rate was higher, whereas in infected rat myocytes, beat rate was slower and less rhythmic. Studies also revealed that variability in interbeat interval was much higher in infected neonatal rat cardiac myocytes (de Carvalho et al., 1992); mouse myocytes exhibited decreased chronotropic response to norepinephrine (Aprigliano et al., 1993), whereas rat heart cells showed the opposite effect (Bergdolt et al., 1994). The extent to which these differences reflect parasite strain is unknown, but the strikingly different effects that parasite strain can cause are illustrated by a 
recent gene profiling experiment performed on $\mathrm{L}_{6} \mathrm{E}_{9}$ myoblasts infected with four different T. cruzi species that identified distinct transcriptomic fingerprints caused by each parasite (Adesse et al., 2010).

Studies in both rat (de Carvalho et al., 1992; see Fig. 3.2) and mouse cardiac myocytes following infection with Y or Tulahuan strains of T. cruzi (Adesse et al., 2008; de Carvalho et al., 1992) demonstrated that Cx43 immunofluorescence in infected cell pairs was substantially lower at $72 \mathrm{~h}$ after infection; coupling between non-parasitized cells in infected dishes was not affected, indicating that factors secreted into the medium are unlikely to be responsible for the decrease in $\mathrm{Cx} 43$ abundance by infected myocytes. Junctional conductance and dye transfer were also measured electrophysiologically at $72 \mathrm{~h}$ after infection in the rat myocytes (de Carvalho et al., 1992), and those results indicated a strong decrease in coupling, but only in cases where both cells were infected.

We also have examined expression of the major cardiac gap junction protein $\mathrm{Cx} 43$ employing immunoblots and RNA measurement. In both rat and mouse, Western blots of Cx43 protein and Northern blots of Gja1 mRNA indicated only slightly decreased levels in rat astrocytes and leptomeningeal cells at up to $72 \mathrm{~h}$ after infection in culture (Campos de Carvalho et al., 1998). This only slight decrease in Cx43 mRNA at later time points in culture is consistent with recent microarray studies described below. However, immunofluorescence has uniformly detected strikingly less $\mathrm{Cx} 43$ in junctional regions of infected rat cells. Such a dramatic decrease in Cx43 immunostaining without major change in total $\mathrm{Cx} 43$ protein might indicate that an antigenic site became "cryptic" as a consequence of parasitic infection (as was reported to occur between CNS glial cells in kainate-induced excitotoxicity; Hossain et al., 1994). However, similar results were obtained using other $\mathrm{Cx} 43$ antibodies, and we suggested initially that the infection altered Cx43 distribution within the cell, presumably as a result of altered trafficking and retention in non-junctional compartments (de Carvalho et al., 1992, 1994).

Another peculiarity with regard to $\mathrm{Cx} 43$ immunostaining arose in initial studies using an antibody (181A) raised by Dr. Elliot Hertzberg against an epitope on the carboxyl terminus of $\mathrm{Cx} 43$. This antibody seemed to stain the intracellular parasite, raising the possibility that T. cruzi might either express $\mathrm{Cx} 43$ or highjack it intracellularly. However, the use of antibodies directed to different residues of the cytoplasmic $\mathrm{Cx} 43 \mathrm{C}$-terminal tail demonstrated that a $T$. cruzi surface protein actually cross-reacts with certain $\mathrm{Cx} 43$ antibodies. As illustrated in Fig. 3.3, immunogold analysis using the 181 A antibody (residues 346-360) displayed typical localization at cell-cell contacts in non-infected cardiac myocytes (Fig. 3.3A, arrows). However, in T. cruzi-infected cells, membrane Cx43 immunolocalization was absent and there was consistent staining of the amastigotes (Fig. 3.3B, arrowheads). Confocal microscopy showed that using a commercially available antiCx43 antibody (Sigma), recognizing an adjacent region (residues 363-382) of the C-tail, there was no staining of the intracellular parasites (Fig. 3.3C). Highly infected cardiac cells lose $\mathrm{Cx} 43$ immunoreactivity for both Sigma and 181A antibodies (Fig. 3.3C and D, stars), but non-parasitized cells displayed normal $\mathrm{Cx} 43$ plaques (Fig. 3.3C and D, arrows). Thus, staining of $T$. cruzi by $181 \mathrm{~A}$ antiserum is likely due to the recognition of a homologous protein, present in all three life forms of the parasite (Fig. 3.3F), showing a different molecular weight from $\mathrm{Cx} 43$ as compared to mouse heart lysates used as positive controls. Staining of a 120-kDa band was observed in immunoblots using the 181 A antibody (Fig. 3.3F) but not with the Sigma antibody (Fig. 3.3E).

Our previous observations (Bergdolt et al., 1994; Garzoni et al., 2003) and those of others (Rodriguez et al., 1995) demonstrated that intracellular calcium concentrations in the host cell were increased during initial times of infection with trypomastigotes and that these 
calcium waves could propagate in a cluster of neighbouring cells (Garzoni et al., 2003). To re-examine the issue of whether $T$. cruzi invasion could modulate gap junctional communication, we examined $\mathrm{Cx} 43$ expression/distribution in mouse cardiac myocytes during initial infection with the $\mathrm{Y}$ strain. In cultured mouse myocytes, the infection with the Y strain of $T$. cruzi had an interesting effect on Cx43 expression. At the first hour of infection, which corresponds to initial steps of this interaction, $\mathrm{Cx} 43$ protein levels were substantially increased, whereas $\mathrm{Cx} 43$ transcripts were unaltered (Fig. 3.4). These observations suggest an effect of parasite invasion on connexin trafficking: As T. cruzi depends on lysosome recruitment for the formation of the parasitophorous vacuole (Andrade and Andrews, 2004), Cx43 removal from the plasma membrane could be impaired. Further analysis at 24-72 hours post-infection (hpi) revealed a $61 \%$ decrease in protein levels (Fig. 3.4A) and a 20\% decrease in mRNA levels at the final time point (Fig. 3.4), when cells are highly parasitized, with abundant intracellular amastigotes and no $\mathrm{Cx} 43$ staining (Fig. 3.3). The changes in $\mathrm{Cx} 43$ levels detected in mouse cardiac myocytes infected with the $\mathrm{Y}$ strain are in contrast with previous observations on rat glial cells infected with Tulahuan strain, which showed no significant alteration in levels of either $\mathrm{Cx} 43$ or its phosphorylation state at 72 hpi (Campos de Carvalho et al., 1998). These discrepancies could be explained by the differences in parasitaemia (which was considerably lower in the glial study) or in parasite strain pathogenicity in vivo (Caetano et al., 2010) or in vitro, as recently demonstrated in our study that used oligonucleotide microarrays to compare the infection of rat myoblasts with four reference strains of T. cruzi (Adesse et al., 2010).

Thus, there seems to exist a direct relationship between host cell parasitism and $\mathrm{Cx} 43$ downregulation in vitro, as demonstrated in Figs. 3.3 and 3.4, in which highly infected cells display decreased $\mathrm{Cx} 43$ protein and mRNA levels. This hypothesis is further supported by a recent study that showed recovery of infected myocytes after treatment with amiodarone, a potent anti-arrhythmic that is commonly prescribed for chagasic patients with severe cardiac compromise (Dubner et al., 2008). Interestingly, this compound is also an inhibitor of sterol biosynthesis in fungi (Courchesne, 2002; Courchesne et al., 2009) and trypanosomatids (Benaim et al., 2006; Serrano-Martín et al., 2009). When used in micromolar concentrations $(1.6-6.5 \mu \mathrm{g} / \mathrm{ml})$ in infected myocyte cultures, amiodarone induced profound morphological alterations to amastigotes that led to clearance of the parasitism and host cell recovery. Among the changes observed was a marked recovery of $\mathrm{Cx} 43$ immunoreactivity and spontaneous contractility rate (Adesse et al., 2011). These observations, combined with that of minimal change in $\mathrm{Cx} 43$ transcripts during in vitro infection (Fig. 3.4), reinforce the idea that the $\mathrm{Cx} 43$ protein downregulation that follows in vitro infection results from impaired protein synthesis, rather than altered $\mathrm{Cx} 43$ gene expression. Amiodarone is a promising compound, as it has a strong bioavailability, is highly lipophilic (Van Herendael and Dorian, 2010) and selectively eradicates $T$. cruzi infection in doses much lower than what is recommended by the American Heart Association for daily dosage in cases of atrial fibrillation (200-400 mg/day) with no side effects (Schweizer et al., 2011).

The murine models of chagasic infection have brought important contributions to the understanding of the arrhythmogenic impact of $\mathrm{Cx} 43$ remodelling. During acute infection with $T$. cruzi (11 days post-infection with the Y strain or 30 days post-infection with the Brazil strain), Cx43 protein levels are decreased in atria and ventricles, consistent with what was observed in the in vitro infection (Adesse et al., 2008). Such a reduction in overall $\mathrm{Cx} 43$ abundance in the infected heart presumably reflects inhomogeneous distribution, a condition that is a prominent feature of ventricular conduction disorders (see Severs, 2001 for review). The reduction in the expression of Cx43 levels in the infected heart may be induced by the parasite per se. However, the effects of soluble factors present in the serum and the inflammatory response on $\mathrm{Cx} 43$ expression cannot be entirely ruled out. When serum from chagasic cardiomyopathic patients was added to cultured cardiomyocytes or isolated rabbit 
hearts, there was a substantial impairment of dye spread through gap junctions, atrioventricular conduction block and changes in heart rate (Costa et al., 2000). This observation seems to contradict the results described above, in which we observed substantial impairment in the coupling and $\mathrm{Cx} 43$ expression of infected cells but not in nonparasitized cells in infected dishes (Adesse et al., 2008, de Carvalho et al., 1992). The difference between these data could be in part explained by the high concentrations of serum proinflammatory cytokines and chemokines found during chronic infection in which parasite load is much reduced. It has been shown that growth factors, such as transforming growth factor- $\beta$ (TGF- $\beta$ ), can regulate gap junction intercellular communication (Chandross et al., 1995; see Chanson et al., 2005 for review). TGF- $\beta$ is required for the invasion of host cells and is produced early upon infection, and constantly throughout the acute and chronic phases (see Araújo-Jorge et al., 2008 for review). Recently, it was demonstrated that the addition of $2 \mathrm{ng} / \mathrm{mL}$ TGF- $\beta$ in cardiomyocytes in vitro downregulated $\mathrm{Cx} 43$ protein expression in non-infected myocytes, resulting in reduced organization of gap junctions similar to the pattern observed in infected cultures. These results were further reinforced when the TGF- $\beta$ receptor type 1 (ALK-5) was inhibited by SB-431542, which completely reversed the effect of TGF- $\beta$ and T. cruzi infection on Cx43 expression. The authors suggested that TGF- $\beta$ produced in infected culture could affect both infected and noninfected cells and affect the pattern of $\mathrm{Cx} 43$. In addition, because TGF- $\beta$ regulates a diverse array of cellular processes, including tissue development and repair (see Ramos-Mondragón et al., 2008, Yarnold and Brotons, 2010 for reviews), the high levels of TGF- $\beta$ and consequent disorganized expression of $\mathrm{Cx} 43$ could both act in synergy to promote dysrhythmias in chagasic patients (Waghabi et al., 2009).

Confocal microscopy experiments revealed that acute infection (30 days post-infection with the Brazil strain) induces connexin remodelling with lateralization of $\mathrm{Cx} 43$ plaques, that is, delocalization from the intercalated discs (Fig. 3.5A-B). Such remodelling is commonly observed in cardiac diseases such as hypertrophic cardiomyopathy (Seidel et al., 2010), myocardial infarction (Wang et al., 2010) and heart failure (Akar et al., 2004) and contributes to impairment of impulse propagation.

In a murine model of chronic $T$. cruzi infection (Y strain), we observed structural damage to the myofibrils, mitochondria and sarcoplasmic reticulum with intercalated disc discontinuity, as shown in the electron micrographs in Fig. 3.5C and D. Interestingly, using oligonucleotide microarrays, we have previously described that both in in vitro and in in vivo models of infection, there are marked changes in the expression of genes related to contractile proteins as well as to the intercalated disc (Adesse et al., 2010; Goldenberg et al., 2009; Mukherjee et al., 2008). An important recent report indicated that in human chagasic cardiomyopathic hearts, $\mathrm{Cx} 43$ distribution is altered in areas of fibrosis and this observation was most prominent in patients with cardiomegaly (Waghabi et al., 2009). These findings highlight an evolving concept that many types of cardiomyopathy target expression or involve mutations in molecular components of the intercalated disc (see Saffitz et al., 2007 for review and Celes et al., 2007 for changes in sepsis). Thus, as pointed out in recent commentary (Spray and Tanowitz, 2007), cardiomyopathies, including chronic chagasic cardiomyopathy, may be considered to be "junctionopathies". Taken together, these data may explain in part the dysrhythmias and conduction abnormalities that attend this infection (see Section 3.4).

\subsection{NOT ALL JUNCTIONAL PROTEINS ARE AFFECTED BY TRYPANOSOMA CRUZI INFECTION}

As emphasized above, our studies have consistently demonstrated that $T$. cruzi infection decreases Cx43 expression at appositional membranes in cultured cardiac myocytes. In 
order to investigate effects of $T$. cruzi infection on other protein families, we used MardinDarby canine kidney (MDCK) cells to evaluate $\mathrm{Cx} 43$ and the tight junction protein zona occludens-1 (ZO-1) expression after T. cruzi infection (48 h). Immunocytochemistry with antibodies specific for $\mathrm{Cx} 43$ (Fig. 3.6A) demonstrated that gap junctional staining was significantly reduced in most of the infected cells, although uninfected neighbours could display normal $\mathrm{Cx} 43$ abundance and distribution (Fig. 3.6A). Although a number of connexins (including $\mathrm{Cx} 43$ ) are associated with $\mathrm{ZO}$ proteins (Giepmans and Moolenaar, 1998; Sorgen et al., 2004; Toyofuku et al., 1998), the infection did not affect the ZO-1 tight junction proteins in MDCK cells (Fig. 3.6B). These results demonstrate that T. cruzi infection disrupts specifically $\mathrm{Cx} 43$ gap junction protein and spares several proteins that form tight junctions (F. Fortes, A.C. Campos de Carvalho and R. Goldenberg, unpublished observations).

\subsection{MICROARRAY EXPERIMENTS HAVE REVEALED PROFOUND CHANGES IN GENE EXPRESSION IN THE CHAGASIC MOUSE, BOTH IN ACUTE AND IN CHRONIC DISEASE PHASES}

We have published several papers characterizing the impact of chagasic cardiomyopathy and acute infection of neonatal rodent myocytes on gene expression by host tissue or cells (Adesse et al., 2010; Goldenberg et al., 2009; Manque et al., 2011; Mukherjee et al., 2003; 2008; Soares et al., 2010). Our most extensive data set involved hybridization on Duke oligonucleotide arrays of RNA extracted from four biological replicas of hearts from control and C57B16 mice infected with the Colombian strain of T. cruzi for 8 months (i.e. chronic stage) (Soares et al., 2010). For this chapter, we further analyzed those data with respect to heart rhythm determinant (HRD) genes selected using our prominent gene expression analysis (PGA; Iacobas et al., 2010a). In this data set, Cx43 (Gjal) was slightly but not significantly reduced (1.8-fold reduction, $p=0.07$ ), whereas $\mathrm{Cx} 37$, the major gap junction protein in endothelial cells, was strongly upregulated (3.3-fold, $p=0.02)$. Of the cadherins $(\mathrm{Cdh})$ for which there were adequate data $(\mathrm{Cdh} 4,5$ and 13$)$, only $\mathrm{Cdh} 13$ was regulated $(-1.7$-fold, $p=0.02)$. Other HRD genes downregulated include those encoding the inwardly rectifying potassium channel $\mathrm{J} 8(-1.6, p<0.04)$ and Pklaa $(-1.7, p=0.01)$. Upregulated HRD genes included Lamin A (1.7-fold, $p=0.04$ ), Myh7 (2.7-fold, $p=0.006)$ and TGF 2 (1.9-fold, $p=0.005)$. Some other genes encoding proteins that have been associated with $\mathrm{Cx} 43$ were not significantly affected, including $\mathrm{Cx} 40$ and $\mathrm{Cx} 45$, catenins, CAR and plakophilin. Another metric by which to examine the impact of disease on experimental intervention is to use coordination analysis to determine the degree to which network interlinkage is altered. Results of such a network analysis are shown in Fig. 3.7, where we have compared the extent to which HRD genes are $(p<0.05)$ synergistically (Pearson coefficients $>0.9$ ) or antagonistically (Pearson coefficients $<-0.9$ ) coordinately expressed among themselves (Fig. 3.7A-D) and with connexins. Inspection of the networks in normal heart reveals that there are many synergistic interlinkages and very few antagonistic connections (Fig. 3.7A and B); in the infected heart, synergistic connections are reduced, whereas antagonistic ones are greatly increased (Fig. 3.7C and D). This network remodelling is especially evident when the interlinkages are focused on connexin genes in control and infected hearts (Fig. 3.7E). With respect to individual gap junction genes, Cx43 (Gjal) is synergistically expressed with five genes (Gja4, Gjc1, Cav3, Ctmd1, Scr5a), Gja4 with eight (Gja1, Cdh5, Ctnna2, Dsg2, Epas1, Pcdh18, Scn5a and Tjap1), Gja5 with six (Atplal, Dsc2, Pcd1, Pcdhga12, Tgfb2 and Tjap1) and Gjc1 with four (Gja1, Ctnnd1, Cxad5, Pcdh7). By contrast, these interlinkages are radically different in $T$. cruzi-infected heart. Gja1 is synergistically expressed with six genes (Gja5, Ank3, Pdch18, Pcdhga12, Ryr2 and Tjp1) and antagonistically with three genes (Gjc1, Cdh5 and Lmma1). Gja4 becomes synergistically expressed with only two genes (Adrbk1 and Ctnnall) and antagonistically 
with eight (Abcc9, Casq2, Cdhl2, Csrp3, Cxddr, Gaa, Kcnj8, Pbp2). Gja5 becomes synergistically expressed with three genes (Gja1, Tjp1 and Ttn) and antagonistically with only two (Gjc2 and Pcdh1). Gjc1 becomes synergistically expressed with five genes (Cay3, Cdh5, tmnd1, Hand2 and Pcdh1) and antagonistically with six (Gjal, Gja5, Atpla1, Epas1, Tjap1 and Tjp1). These pairwise interconnections among HRD genes are illustrated in Fig. 3.7A-B, showing the remarkable extent of alteration in response to parasitic infection. Although the resulting altered topology is specific for Chagas disease, profound remodelling of the HRD genomic fabric was also reported in other arrhythmogenic conditions such as chronic constant and intermittent hypoxia (Iacobas et al., 2010b).

\subsection{CONCLUSIONS}

Chagas disease is the result of infection with $T$. cruzi. Acute infection is accompanied by an acute myocarditis with myonecrosis, inflammation and intracellular parasites. Despite the small number of cells that are infected, nevertheless, there is often functional deterioration, manifested both as arrhythmias and as compromised cardiac output. Infection of cultured cardiac myocytes can be viewed as an in vitro correlate of acute infection of the heart. These infected cultured cells display altered chronotropy and synchronous activity even though few cells are infected. This suggests that there are signals sent out from infected cell to noninfected cells that may alter the physiological responses of cells within the whole culture dish. This is likely similar to what occurs in the heart with alterations in gap junctions as a result of infection. Chronic chagasic heart disease is associated with profound conduction disturbances associated with fibrosis, lipid accumulation and cellular and tissue level hypertrophy. We now appreciate that even during the chronic phase of the disease, there is a persistence of the parasite with a low-level continuous infection that is associated with fibrosis and vasculopathy. In part, this manifestation of dysfunction as a consequence of only a small number of cells being affected may reflect the anatomy of the tissue that is targeted. The heart is composed of specialized conduction and contraction myocytes, and optimized output depends upon the progressive synchronized activation of the contractile myocardium. Thus, reducing gap junction expression in only a small number of cells could provide focal slowing of conduction or focal compromise of chamber contraction.

Infection of cardiac myocytes and more globally, infection of the animal, leads to functional uncoupling of cardiac myocytes, as a consequence of reduced expression of $\mathrm{Cx} 43$ and its gene. A variety of methods have been used to evaluate the changes in gap junction expression in the chagasic heart. These methods include functional studies in which dye coupling, junctional conductance or conduction synchrony were evaluated, by immunostaining and Western blotting and measurements of gene expression, either through Northern blots or, more recently, from microarray analysis. The findings from these studies include the observation that the cardiac gap junction protein and the channels that it forms are a target of infection. In a population of acutely infected cardiac myocytes, gap junction abundance and immunoreactivity with certain antibodies are severely compromised, as are functional coupling and synchronous contraction. In adjacent non-infected cells, gap junction expression and function are less affected so that there is a mosaic of cells that are either connected or disconnected to their neighbours depending on presence and extent of parasitaemia. In chronic chagasic cardiomyopathy, the number of parasitized cells is low, but circulating factors such as IL- $1 \beta$ and TGF- $\beta$ are elevated in the chronically inflamed myocardium, resulting in not only reduced expression of $\mathrm{Cx} 43$ but also structural remodelling due to fibrosis.

In summary, the available data suggest that the effect on gap junctions of small numbers of infected cells in both acute and chronic disease has a critical role in the underlying pathophysiological processes which result in clinical chagasic cardiomyopathy. 


\section{REFERENCES}

Adesse D, Garzoni LR, Huang H, Tanowitz HB, de Nazareth Meirelles M, Spray DC. Trypanosoma cruzi induces changes in cardiac connexin43 expression. Microbes Infect. 2008; 10:21-28. [PubMed: 18068391]

Adesse D, Iacobas DA, Iacobas S, Garzoni LR, Meirelles Mde N, Tanowitz HB, et al. Transcriptomic signatures of alterations in a myoblast cell line infected with four distinct strains of Trypanosoma cruzi. Am. J. Trop. Med. Hyg. 2010; 82:846-854. [PubMed: 20439965]

Adesse D, Azzam EM, Meirelles Mde N, Urbina JA, Garzoni LRA. Miodarone inhibits Trypanosoma cruzi infection and promotes cardiac cell recovery with gap junction and cytoskeleton reassembly in vitro. Antimicrob. Agents Chemother. 2011; 55:203-210. [PubMed: 21078932]

Akar FG, Spragg DD, Tunin RS, Kass DA, Tomaselli GF. Mechanisms underlying conduction slowing and arrhythmogenesis in nonischemic dilated cardiomyopathy. Circ. Res. 2004; 1:717-725. [PubMed: 15345654]

Andrade LO, Andrews NW. Lysosomal fusion is essential for the retention of Trypanosoma cruzi inside host cells. J. Exp. Med. 2004; 1:1135-1143. [PubMed: 15520245]

Aprigliano O, Masuda MO, Meirelles MN, Pereira MC, Barbosa HS, Barbosa JC. Heart muscle cells acutely infected with Trypanosoma cruzi: characterization of electrophysiology and neurotransmitter responses. J. Mol. Cell. Cardiol. 1993; 25:1265-1274. [PubMed: 8263957]

Araújo-Jorge TC, Waghabi MC, Soeiro Mde N, Keramidas M, Bailly S, Feige JJ. Pivotal role for TGF-beta in infectious heart disease: the case of Trypanosoma cruzi infection and consequent Chagasic myocardiopathy. Cytokine Growth Factor Rev. 2008; 19:405-413. [PubMed: 18938102]

Benaim G, Sanders JM, Garcia-Marchán Y, Colina C, Lira R, Caldera AR, et al. Amiodarone has intrinsic anti-Trypanosoma cruzi activity and acts synergistically with posaconazole. J. Med. Chem. 2006; 9:892-899. [PubMed: 16451055]

Bergdolt BA, Tanowitz HB, Wittner M, Morris SA, Bilezikian JP, Moreno AP, et al. Trypanosoma cruzi: effects of infection on receptor-mediated chronotropy and $\mathrm{Ca} 2+$ mobilization in rat cardiac myocytes. Exp. Parasitol. 1994; 78:149-160. [PubMed: 8119371]

Caetano LC, do Prado JC Jr. Toldo MP, Abrahão AA. Trypanosoma cruzi: do different sylvatic strains trigger distinct immune responses? Exp. Parasitol. 2010; 124:219-224. [PubMed: 19786023]

Campos de Carvalho AC, Roy C, Hertzberg EL, Tanowitz HB, Kessler JA, Weiss LM, et al. Gap junction disappearance in astrocytes and leptomeningeal cells as a consequence of protozoan infection. Brain Res. 1998; 790:304-314. [PubMed: 9593958]

Celes MR, Torres-Dueñas D, Alves-Filho JC, Duarte DB, Cunha FQ, Rossi MA. Reduction of gap and adherens junction proteins and intercalated disc structural remodeling in the hearts of mice submitted to severe cecal ligation and puncture sepsis. Crit. Care Med. 2007; 35:2176-2185. [PubMed: 17855834]

Chaldoupi SM, Loh P, Hauer RN, de Bakker JM, van Rijen HV. The role of connexin40 in atrial fibrillation. Cardiovasc. Res. 2009; 84:15-23. [PubMed: 19535379]

Chandross KJ, Chanson M, Spray DC, Kessler JA. Transforming growth factorbeta 1 and forskolin modulate gap junctional communication and cellular phenotype of cultured Schwann cells. J. Neurosci. 1995; 15:262-273. [PubMed: 7823132]

Chanson M, Derouette JP, Roth I, Foglia B, Scerri I, Dudez T, et al. Gap junctional communication in tissue inflammation and repair. Biochim. Biophys. Acta. 2005; 1711:197-207. [PubMed: 15955304]

Costa PC, Fortes FS, Machado AB, Almeida NA, Olivares EL, Cabral PR, et al. Sera from chronic chagasic patients depress cardiac electrogenesis and conduction. Braz. J. Med. Biol. Res. 2000; 33:439-446. [PubMed: 10775309]

Courchesne WE. Characterization of a novel, broad-based fungicidal activity for the antiarrhythmic drug amiodarone. J. Pharmacol. Exp. Ther. 2002; 300:195-199. [PubMed: 11752116]

Courchesne WE, Tunc M, Liao S. Amiodarone induces stress responses and calcium flux mediated by the cell wall in Saccharomyces cerevisiae. Can. J. Microbiol. 2009; 55:288-303. [PubMed: 19370072] 
de Carvalho AC, Tanowitz HB, Wittner M, Dermietzel R, Roy C, Hertzberg EL, et al. Gap junction distribution is altered between cardiac myocytes infected with Trypanosoma cruzi. Circ. Res. 1992; 70:733-742. [PubMed: 1551199]

de Carvalho AC, Masuda MO, Tanowitz HB, Wittner M, Goldenberg RC, Spray DC. Conduction defects and arrhythmias in Chagas' disease: possible role of gap junctions and humoral mechanisms. J. Cardiovasc. Electrophysiol. 1994; 5:686-698. [PubMed: 7804521]

Dubner S, Schapachnik E, Riera AR, Valero E. Chagas disease: state-of-the-art of diagnosis and management. Cardiol. J. 2008; 15:493-504. [PubMed: 19039752]

Duffy HS, Fort A, Spray DC. Cardiac connexins: genes to nexus. Adv. Cardiol. 2006; 42:1-17. [PubMed: 16646581]

Garzoni LR, Masuda MO, Capella MM, Lopes AG, de Meirelles Mde N. Characterization of [Ca2+]i responses in primary cultures of mouse cardiomyocytes induced by Trypanosoma cruzi trypomastigotes. Mem. Inst. Oswaldo Cruz. 2003; 98:487-493. [PubMed: 12937759]

Giepmans BN, Moolenaar WH. The gap junction protein connexin43 interacts with the second PDZ domain of the zona occludens-1 protein. Curr. Biol. 1998; 13:931-934. [PubMed: 9707407]

Goldenberg RC, Iacobas DA, Iacobas S, Rocha LL, da Silva de Azevedo Fortes F, Vairo L, et al. Transcriptomic alterations in Trypanosoma cruzi-infected cardiac myocytes. Microbes Infect. 2009; 11:1140-1149. [PubMed: 19729072]

Goodenough DA, Goliger JA, Paul DL. Connexins, connexons, and intercellular communication. Annu. Rev. Biochem. 1996; 65:475-502. [PubMed: 8811187]

Hervé JC, Bourmeyster N, Sarrouilhe D. Diversity in protein-protein interactions of connexins: emerging roles. Biochim. Biophys. Acta. 2004; 23:22-41.

Hossain MZ, Sawchuk MA, Murphy LJ, Hertzberg EL, Nagy JI. Kainic acid induced alterations in antibody recognition of connexin43 and loss of astrocytic gap junctions in rat brain. Glia. 1994; 10:250-265. [PubMed: 8056437]

Iacobas DA, Iacobas S, Thomas N, Spray DC. Sex-dependent gene regulatory networks of the heart rhythm. Funct. Integr. Genomics. 2010a; 10:73-86. [PubMed: 19756788]

Iacobas DA, Iacobas S, Haddad GG. Heart rhythm genomic fabric in hypoxia. Biochem. Biophys. Res. Commun. 2010b; 391(4):1769-1774. [PubMed: 20044980]

Manque PA, Probst C, Pereira MCS, Rampazzo RCP, Ozaki LS, Pavoni DP, et al. Trypanosoma cruzi infection induces a global host cell response in cardiomyocytes. Infect. Immun. 2011; 79:18551862. [PubMed: 21343357]

Marin-Neto JA, Cunha-Neto E, Maciel BC, Simões MV. Pathogenesis of chronic Chagas heart disease. Circulation. 2007; 115:1109-1123. [PubMed: 17339569]

Mukherjee S, Belbin TJ, Spray DC, Iacobas DA, Weiss LM, Kitsis RN, et al. Microarray analysis of changes in gene expression in a murine model of chronic chagasic cardiomyopathy. Parasitol. Res. 2003; 91:187-196. [PubMed: 12910413]

Mukherjee S, Nagajyothi F, Mukhopadhyay A, Machado FS, Belbin TJ, Campos de Carvalho A, et al. Alterations in myocardial gene expression associated with experimental Trypanosoma cruzi infection. Genomics. 2008; 91:423-432. [PubMed: 18343633]

Ramos-Mondragón R, Galindo CA, Avila G. Role of TGF-beta on cardiac structural and electrical remodeling. Vasc. Health Risk Manag. 2008; 4:1289-1300. [PubMed: 19337543]

Rodriguez A, Rioult MG, Ora A, Andrews NW. A trypanosome-soluble factor induces IP3 formation, intracellular Ca2+ mobilization and microfilament rearrangement in host cells. J. Cell Biol. 1995; 129:1263-1273. [PubMed: 7775573]

Saffitz JE, Hames KY, Kanno S. Remodeling of gap junctions in ischemic and nonischemic forms of heart disease. J. Membr. Biol. 2007; 218:65-71. [PubMed: 17585361]

Schweizer PA, Becker R, Katus HA, Thomas D. Dronedarone:current evidence for its safety and efficacy in the management of atrial fibrillation. Drug Des. Dev. Ther. 2011; 5:27-39.

Seidel T, Salameh A, Dhein S. A simulation study of cellular hypertrophy and connexin lateralization in cardiac tissue. Biophys. J. 2010; 99:2821-2830. [PubMed: 21044579]

Serrano-Martín X, García-Marchan Y, Fernandez A, Rodriguez N, Rojas H, Visbal G, et al. Amiodarone destabilizes intracellular Ca2+ homeostasis and biosynthesis of sterols in Leishmania mexicana. Antimicrob. Agents Chemother. 2009; 53:1403-1410. [PubMed: 19164149] 
Severs NJ. Gap junction remodeling and cardiac arrhythmogenesis: cause or coincidence? J. Cell. Mol. Med. 2001; 5:355-366. [PubMed: 12067469]

Severs NJ, Dupont E, Thomas N, Kaba R, Rothery S, Jain R, et al. Alterations in cardiac connexin expression in cardiomyopathies. Adv. Cardiol. 2006; 42:228-242. [PubMed: 16646594]

Soares MB, de Lima RS, Rocha LL, Vasconcelos JF, Rogatto SR, dos Santos RR, et al. Gene expression changes associated with myocarditis and fibrosis in hearts of mice with chronic chagasic cardiomyopathy. J. Infect. Dis. 2010; 15:416-426. [PubMed: 20565256]

Söhl G, Willecke K. Gap junctions and the connexin protein family. Cardiovasc. Res. 2004; 1:228232.

Sorgen PL, Duffy HS, Sahoo P, Coombs W, Delmar M, Spray DC. Structural changes in the carboxyl terminus of the gap junction protein connexin43 indicates signaling between binding domains for c-Src and zonula occludens-1. J. Biol. Chem. 2004; 279:54695-54701. [PubMed: 15492000]

Spray DC, Tanowitz HB. Pathology of mechanical and gap junctional co-coupling at the intercalated disc: is sepsis a junctionopathy? Crit. Care Med. 2007; 35:2231-2232. [PubMed: 17713381]

Spray, DC.; Suadicani, SO.; Vink, MJ.; Srinivas, M. Gap junction channels and healing-over of injury. In: Sperelakis, N.; Kurachi, Y.; Terzic, A.; Cohen, MV., editors. Heart Physiology and Pathophysiology. Academic Press; New York: 2001. p. 149-172.

Tanowitz HB, Kirchhoff LV, Simon D, Morris SA, Weiss LM, Wittner M. Chagas' disease. Clin. Microbiol. Rev. 1992; 5:400-419. [PubMed: 1423218]

Tanowitz HB, Machado FS, Jelicks LA, Shirani J, de Carvalho AC, Spray DC, et al. Perspectives on Trypanosoma cruzi-induced heart disease (Chagas disease). Prog. Cardiovasc. Dis. 2009; 51:524539. [PubMed: 19410685]

Toyofuku T, Yabuki M, Otsu K, Kuzuya T, Hori M, Tada M. Direct association of the gap junction protein connexin-43 with ZO-1 in cardiac myocytes. J. Biol. Chem. 1998; 273:12725-12731. [PubMed: 9582296]

Van Herendael H, Dorian P. Amiodarone for the treatment and prevention of ventricular fibrillation and ventricular tachycardia. Vasc. Health Risk Manag. 2010; 6:465-472. [PubMed: 20730062]

Waghabi MC, Coutinho-Silva R, Feige JJ, Higuchi Mde L, Becker D, Burnstock G, et al. Gap junction reduction in cardiomyocytes following transforming growth factor-beta treatment and Trypanosoma cruzi infection. Mem. Inst. Oswaldo Cruz. 2009; 104:1083-1090. [PubMed: 20140368]

Wang D, Zhang F, Shen W, Chen M, Yang B, Zhang Y, et al. Mesenchymal stem cell injection ameliorates the inducibility of ventricular arrhythmias after myocardial infarction in rats. Int. J. Cardiol. 2010 in press.

Yarnold J, Brotons MC. Pathogenetic mechanisms in radiation fibrosis. Radiother. Oncol. 2010; 97:149-161. [PubMed: 20888056] 


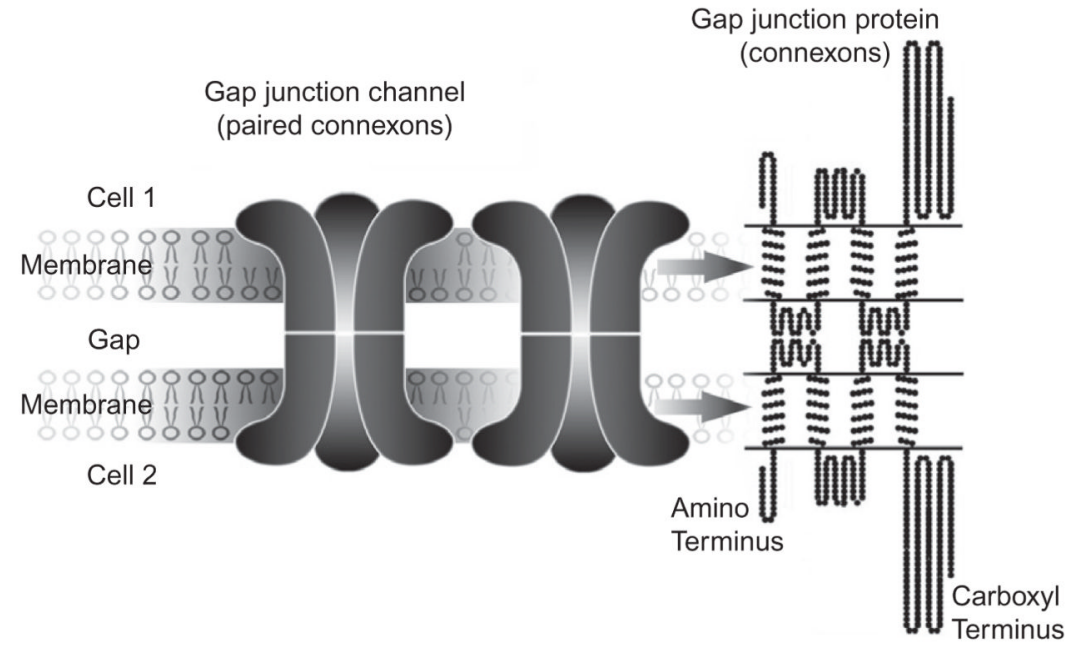

FIGURE 3.1. Schematic representation of gap junction and connexin structures

Two cells are coupled through connexon hemichannels, each composed of six subunits of connexin (Cx). Gap junction channels connect two cells' cytoplasms, allowing free exchange of small metabolites such as $\mathrm{Ca}^{2+}$, IP3 and cAMP, which in heart tissue are important for maintaining synchronous contraction. Gating properties of gap junctions can be regulated by $\mathrm{Cx}$ structure, which consists of four primarily a-helical transmembrane domains, cytoplasmic amino and carboxyl termini and a cytoplasmic loop, all of which contain some regions of $\alpha$-helix, and extracellular loops that are primarily $\beta$-structure. A number of proteins that bind to cardiac connexins are known, and more are certain to be discovered, linking the connexin into an intercellular signalling complex, the Nexus. Binding sites may either correspond to structured regions within the connexin molecules or be unstructured, leading to presumably low-affinity and dynamic interactions. 

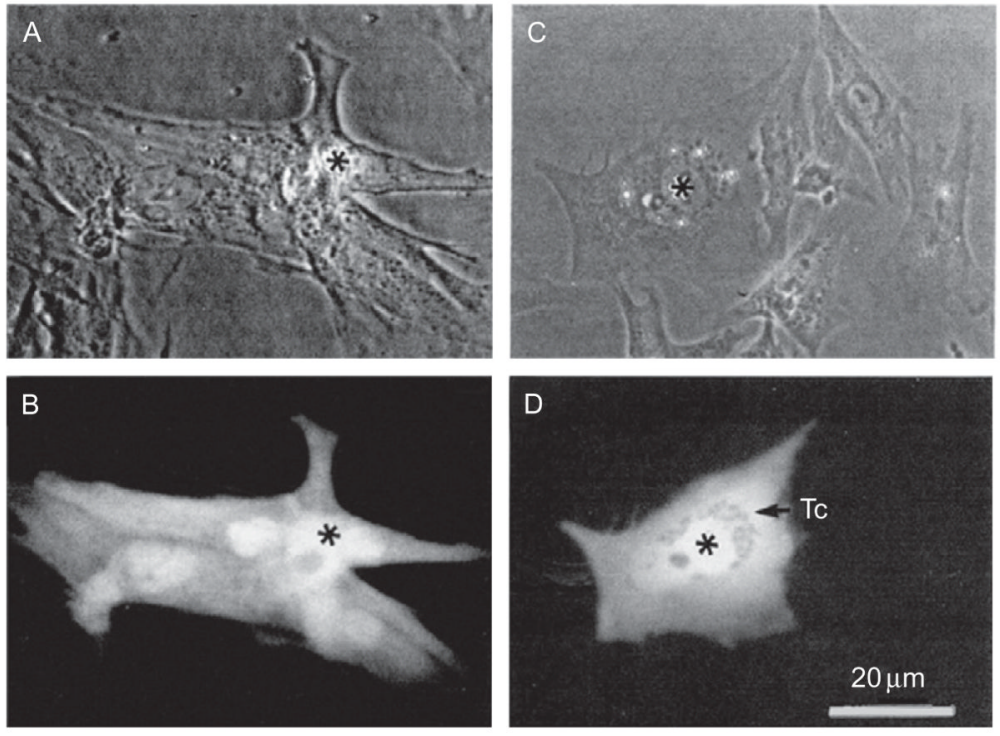

FIGURE 3.2. Trypanosoma cruzi infection impairs cell-cell coupling

The micrographs depict the pioneer experiment that tried to understand the basis of arrhythmogenesis in $T$. cruzi infection. Cultured cardiac myocytes were injected with the dye lucifer yellow (LY) that spreads to adjacent cells through gap junctions. Non-infected cells $(\mathrm{A}, \mathrm{B})$ were capable of transmitting LY to up to six cells, whereas when the injection was done in a highly infected cell (C,D), dye spread was abolished. Asterisks indicate the cells that were injected. Bars $=20 \mu \mathrm{m}$. From de Carvalho et al. (1992). 

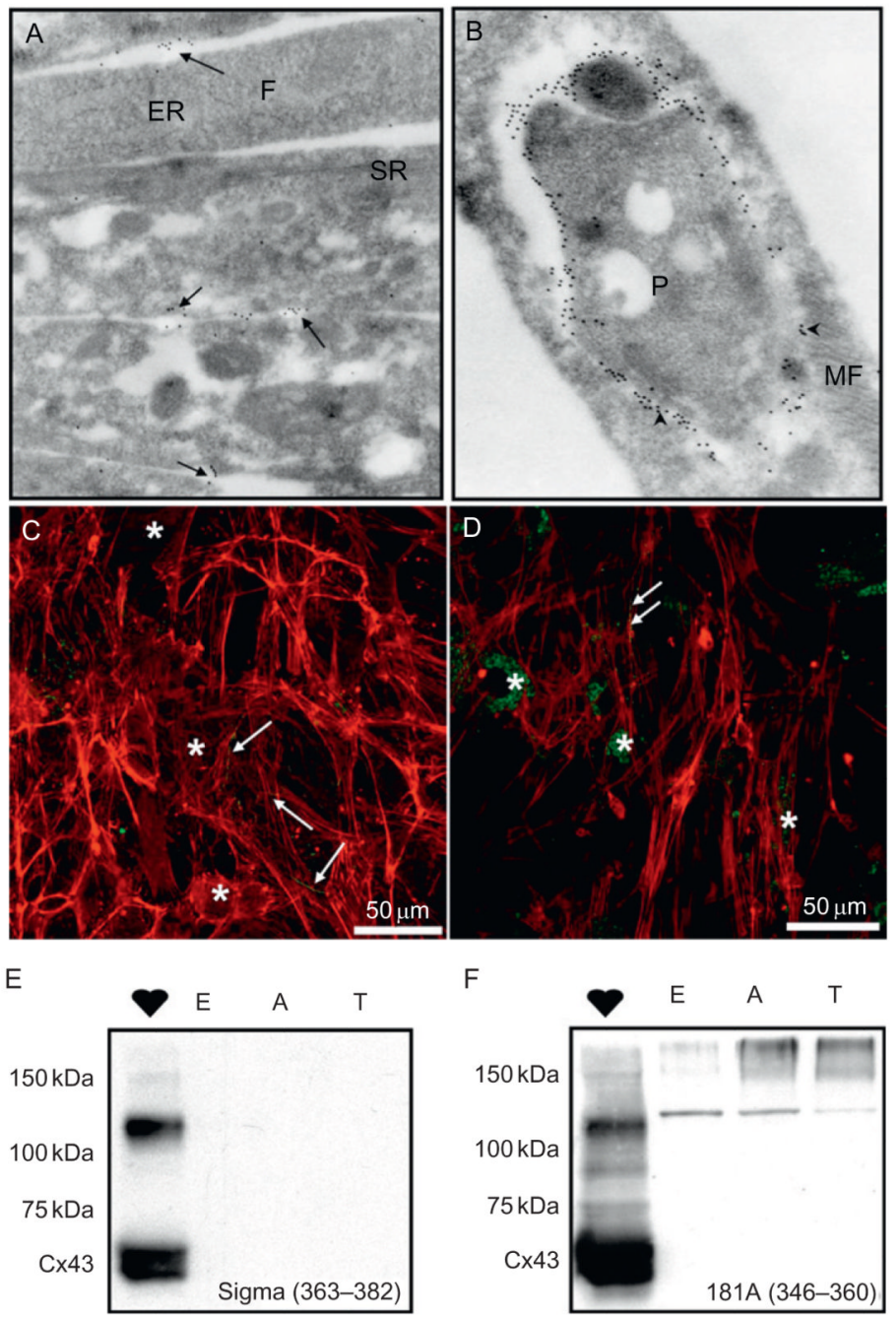

FIGURE 3.3. Does Trypanosoma cruzi express connexin43?

The use of specific antibodies directed to different residues of connexin43 C-terminal tail demonstrated that $\mathrm{Cx} 43$ shares a homologous residue with a $T$. cruzi surface protein. (A and B) Immunogold analysis using the 181A antibody (residues 346-360) displayed typical localization at cell-cell contacts in non-infected cardiac myocytes (A, arrows). However, in T. cruzi infected cells, membrane $\mathrm{Cx} 43$ immunolocalization was absent and there was a consistent staining of the amastigotes (B, arrowheads). Confocal microscopy using a commercially available anti-Cx43 antibody (Sigma), recognizing residues 363-382 of the Ctail, reveals no staining of the intracellular parasites (C). Highly infected cardiac cells lost Cx43 immunoreactivity for both Sigma and 181A antibodies (C and D, stars), but nonparasitized cells displayed normal $\mathrm{Cx} 43$ plaques ( $\mathrm{C}$ and D, arrows). Staining of T. cruzi by 181 A antiserum is likely due to the recognition of a homologous protein, present in all three evolutive forms of the parasite $(\mathrm{F})$, showing a different molecular weight from $\mathrm{Cx} 43$ as compared to mouse heart lysates used as positive controls. Staining of a 120-kDa band was observed in immunoblots using the 181A antibody (F) but not with the Sigma antibody (E). (E, epimastigote; A, amastigote; T, trypomastigote; SR, sarcoplasmic reticulum; ER, endoplasmic reticulum; F, fibroblast; $\mathrm{P}$, parasite; $\mathrm{MF}$, myofibril.) 


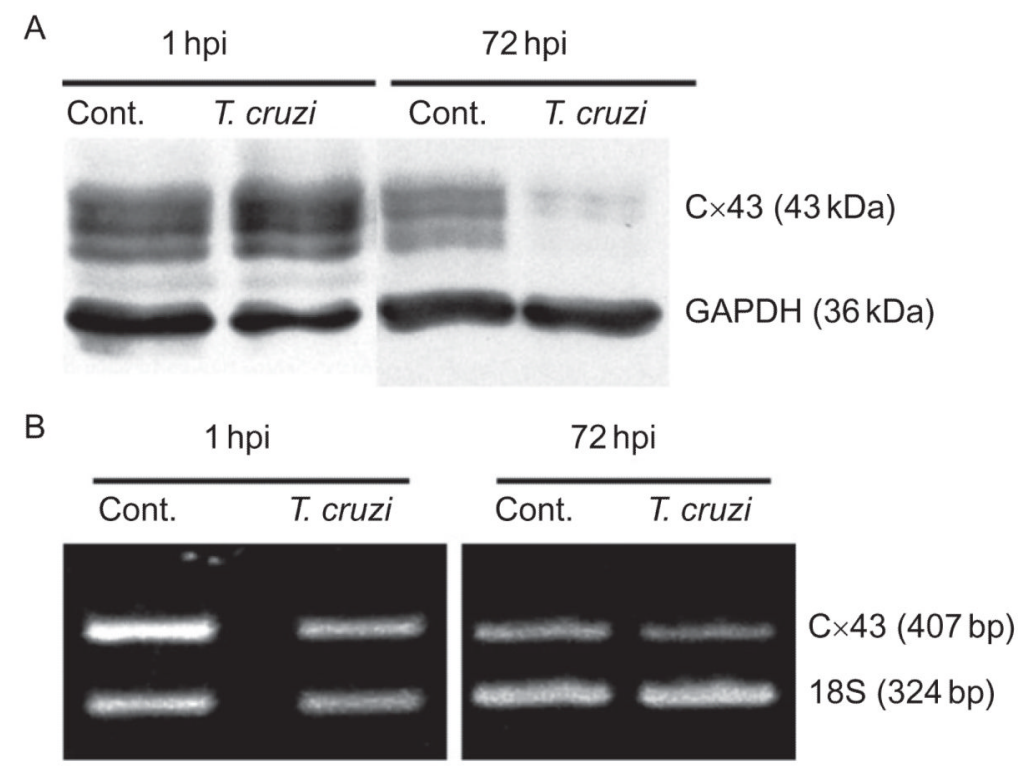

FIGURE 3.4. Connexin43 protein and mRNA expression during in vitro infection with $T$. cruzi Mouse cardiac myocytes were cultivated and infected with the Y strain of $T$. cruzi. Protein analysis showed that infection induces a bidirectional effect on $\mathrm{Cx} 43$, starting with a significant increase at 1 hour post-infection (hpi), followed by a normalization in protein levels until $72 \mathrm{hpi}$, when there is a drop of $61 \%$ in protein levels. Semiquantitative RT-PCR showed no alteration on Cx43 mRNA at $1 \mathrm{hpi}$, but a significant decrease in Cx43 transcripts at $72 \mathrm{~h}$. 

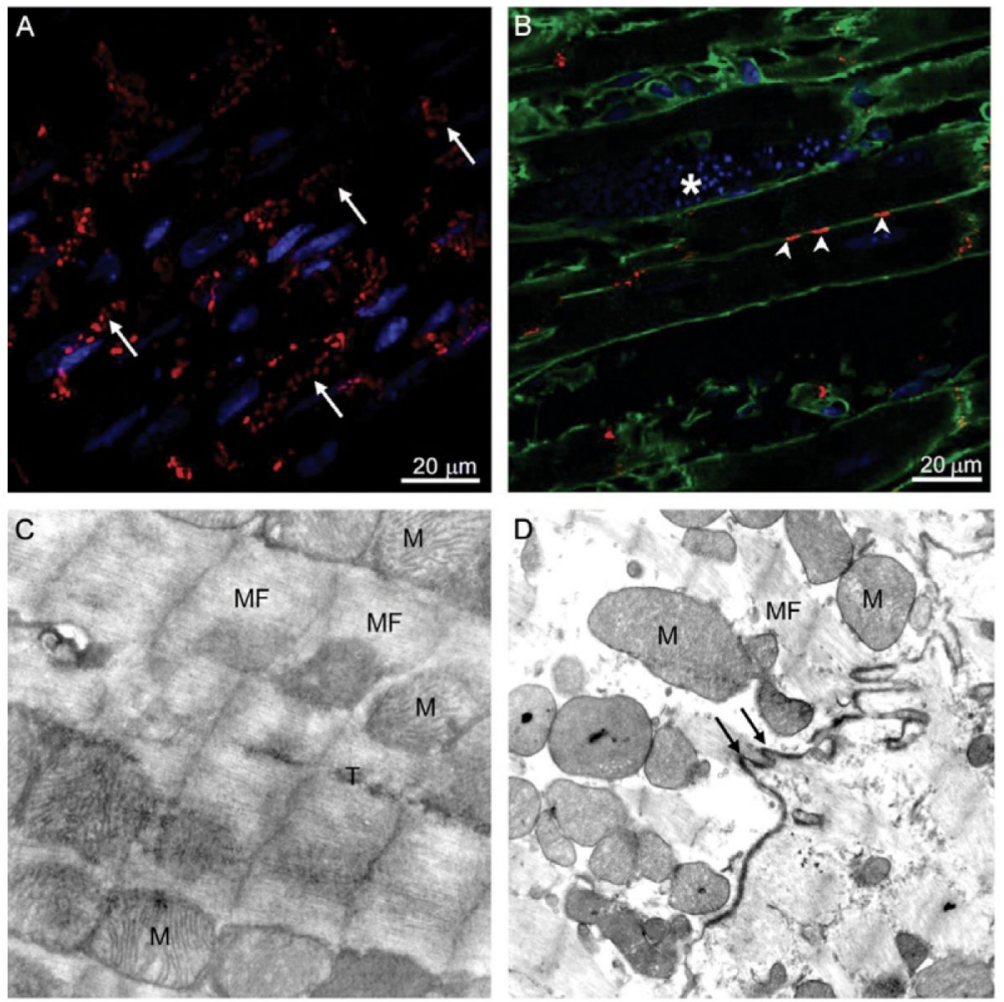

FIGURE 3.5. Cardiac Chagas disease affects connexins and intercalated discs morphology Hearts from acutely infected mice (30 days post-infection with the Brazil strain) were harvested and processed for immunohistochemistry for Cx43 (red) and F-actin (green) (AB). Non-infected animals (A) displayed abundant $\mathrm{Cx} 43$ staining (red) in cell-cell contacts, mainly in the intercalated discs (arrows). Acutely infected myocardium (B) presented amastigotes pseudo-cysts $(*)$, as revealed by DAPI staining in blue and lateralization of Cx43 in neighbour cells (arrowheads). Transmission electron microscopy revealed that during chronic Chagas disease (180 days post-infection with the Y strain), there are foci of severe damage to myocytes (D) in which cells are hypertrophied and display mitochondria swelling and disarray of contractile elements as compared to age-matched uninfected mouse hearts $(\mathrm{C})$. The arrows point to a region where myofibrils anchor to intercalated discs, indicating substantial cellular disorganization. Original magnification: $8000 \times(\mathrm{C})$ and 10,000× (D). M, mitochondria; MF, myofibril; T, T-tubule. 

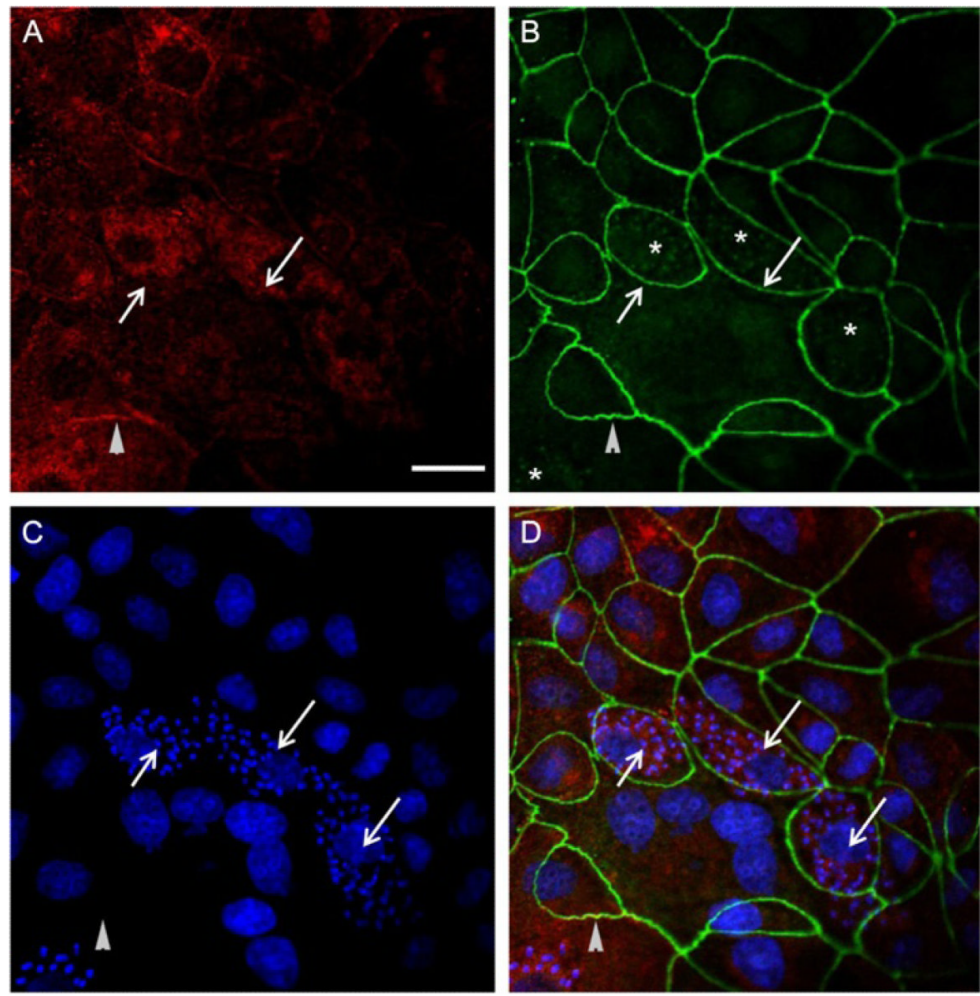

FIGURE 3.6. Trypanosoma cruzi infection affects $\mathrm{Cx} 43$ but not other junctional proteins MDCK2 cells were cultured and infected with $T$. cruzi (Brazil strain) for $72 \mathrm{~h}$.

Immunofluorescence for Cx43 (A, in red) and Zona Occludens-1 (B, in green) showed that despite the drastic decrease in Cx43 immunoreactivity in most of the highly infected cells (*), ZO-1 distribution was maintained intact (arrows mark regions where $\mathrm{Cx} 43$ was lost but ZO-1 was still present, arrowhead where $\mathrm{Cx} 43$ was still present in nonparasitized cells). With nucleic acid staining with TOPRO3, is possible to visualize host cell nuclei and also kinetoplastid DNA from intracellular amastigotes (small spots in (C)). In (D) the merged image is displayed. Bars $=20 \mu \mathrm{m}$. 

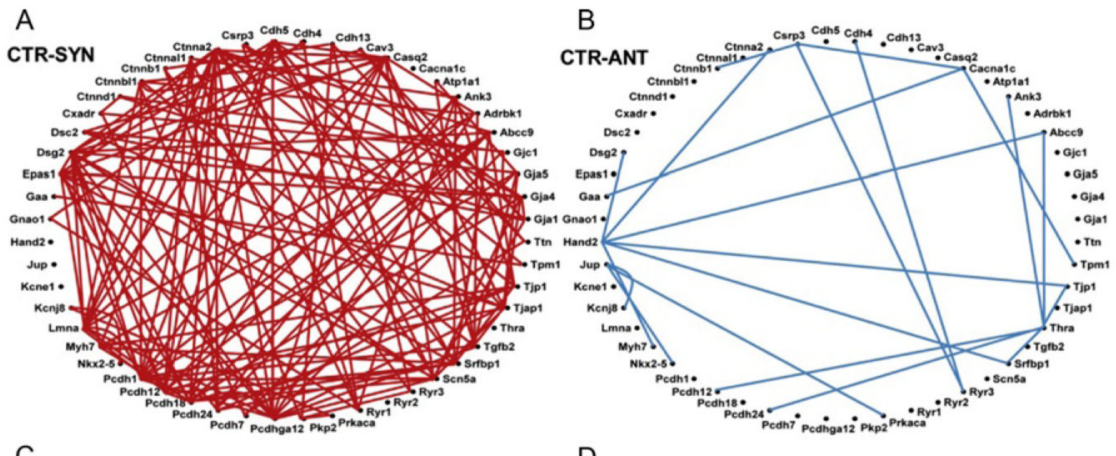

C

D
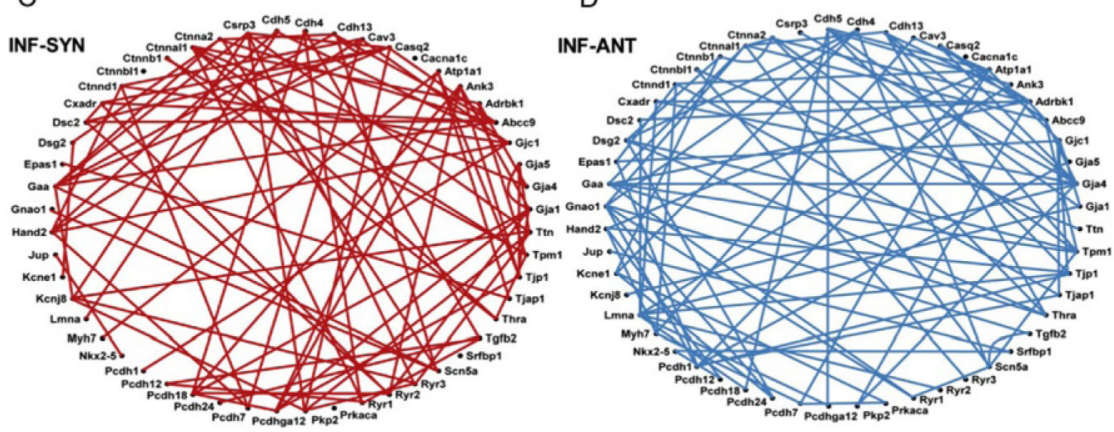

$\mathrm{E}$

$\mathrm{F}$
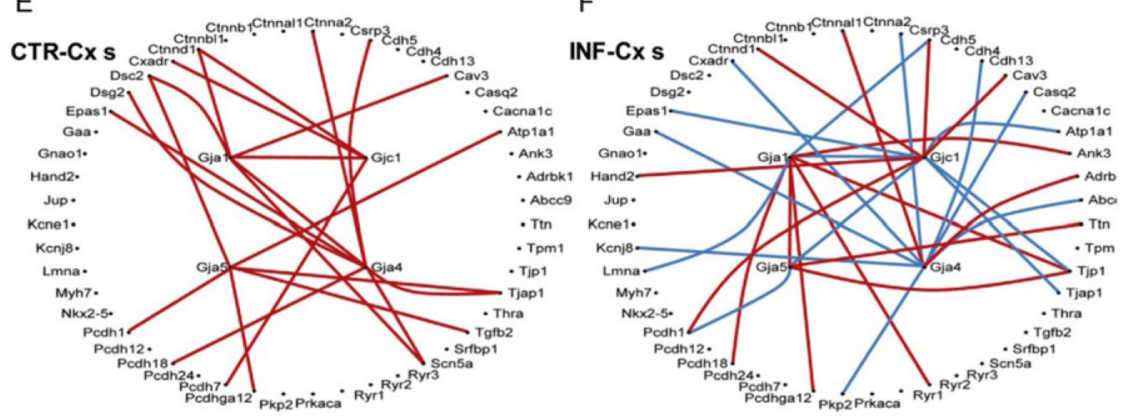

FIGURE 3.7. Remodelling of heart rhythm determinant (HRD) gene interlinkages in the chagasic heart and impact on connexin-dependent HRD networks

(A) Synergistic coordinations (red lines) are very common between HRD gene pairs in normal heart. (B) Antagonistic coordinations (blue lines) between HRD gene pairs are rare in normal heart. (C and D) In infected heart, synergistic coordinations decrease and antagonistic coordinations greatly increase, indicating profound network remodelling ( $\mathrm{E}$ and F). Expression coordinations of connexin genes with HRD genes are substantially altered by T. cruzi infection, with different HRD genes showing synergistic coordination (red lines) and the appearance of numerous antagonistic coordinations. 